\title{
EDITORIAL
}

\section{Cine y psicoanálisis: memorias y luchas}

\author{
Michèle Benhaim
}

Université Aix-Marseille

Los días 6 y 7 de octubre de 2017, la Université Aix Marseille fue escenario de un evento de excepción que articuló el arte y el pensamiento: un Simposio Internacional dedicado al psicoanálisis y el cine, convocado bajo el título Memorias y Luchas. El evento tuvo lugar en la Maison de Recherche en Aix-en-Provence, Francia, auspiciado por el Laboratorio de Psicología Clínica, Psicopatología y Psicoanálisis, bajo la coordinación general de Michèle Benhaim.

Este número especial de Etica\&Cine Journal recoge algunos de los trabajos allí presentados por investigadores, teóricos y cultores del séptimo arte, además de filósofos, críticos de arte, artistas y analistas. Las distintas propuestas son parte de una reflexión en curso sobre los vínculos entre el psicoanálisis, el cine, la psicopatología, la filosofía, la estética, la literatura, el arte y la antropología, en la diversidad de perspectivas teóricas y respeto a las diferencias.

Esta edición bilingue francés-español estuvo al cuidado de Noelia Luzar, docente de Clínica de Adultos y del Departamento de Lengua Francesa de la Universidad de Buenos Aires, quien coordinó un equipo de traductores integrado por Salomé Landívar, Carolina Kasimierski y Sergio Peralta. La revisión técnica estuvo a cargo de los editores de la revista, Mariana Gómez (Universidad Nacional de Córdoba) y Juan Jorge Michel Fariña (Universidad de Buenos Aires). 